\title{
Formação de Leitores: construindo caminhos a partir da sala de aula
}

\section{Formación de lectores: construyendo caminos desde el aula}

\author{
Training of Readers: building paths from the classroom
}

\author{
Adriana Garcia Cabaldi Carvalho' \\ Cristina Pereira Duarte Boéssio ${ }^{2}$
}

\begin{abstract}
Resumo:
O presente estudo apresenta relatos e reflexões sobre as ações da proposta de intervenção, requisito do Mestrado Profissional em Educação, que está sendo desenvolvida com a turma do $4^{\circ}$ ano da EMEF Padre Pagliani no município de Jaguarão, RS. A proposta tem por objetivo geral promover ações que despertem nos alunos o gosto pela leitura, partindo da reconstrução do espaço da sala de aula, e justifica-se pela dificuldade em desenvolver atividades relacionadas à leitura, bem como pelo desinteresse dos alunos. Durante a organização da proposta, foi adquirido um acervo para a turma por meio de doações dos alunos e por aquisição da professora, com livros diferentes dos que a biblioteca da escola possui. A intervenção teve como primeira ação a organização do cantinho da leitura, seguida de contação de histórias. Serão organizadas rodas de leitura, piquenique literário e dramatizações. O acervo da sala é disponibilizado para que os alunos também possam levar os livros para casa, incentivando-os a envolver a família em suas leituras. A proposta acontece em dois encontros por semana. Nas primeiras ações da intervenção pedagógica que está em andamento, a maioria dos alunos já demonstra interesse e participa ativamente.
\end{abstract}

Palavras-chave: formação de leitores; gosto pela leitura; reconstrução do espaço da sala de aula.

\section{Resumen:}

El presente estudio presenta relatos y reflexiones sobre las acciones de la propuesta de intervención, requisito de la Maestría Profesional en Educación, que está siendo desarrollada con la clase del $4^{\circ}$ año de la EMEF Padre Pagliani en el municipio de Jaguarão, RS. La propuesta tiene por objetivo general promover acciones que despiertan en los alumnos el gusto por la lectura, partiendo de la reconstrucción del espacio de la sala de clase, y se justifica por la dificultad en desarrollar actividades en relación a la lectura, así como por el desinterés de los alumnos. Durante la organización de la propuesta, se adquirió un acervo para la clase por medio de donaciones de los alumnos y por adquisición de la profesora, con libros diferentes de los que la biblioteca de la escuela posee. La intervención tuvo como primera acción la organización del rincón de la lectura, seguida de la cuenta de historias. Serán organizadas ruedas de lectura, picnic literario y dramatizaciones. El acervo de la sala está

\footnotetext{
${ }^{1}$ Licenciada em Pedagogia pela Universidade Federal do Pampa. Mestranda em Educação pela Universidade Federal do Pampa - UNIPAMPA - Campus Jaguarão. Atua como professora na rede pública municipal de Jaguarão - RS - Brasil.

2 Doutora em Educação pela Universidade Federal de Pelotas. Professora do Programa de Pós Graduação Mestrado Profissional em Educação - Unipampa - Jaguarão. Professora Adjunta no curso de Letras Português/Espanhol -UNIPAMPA - Campus Jaguarão - RS - Brasil.
} 
disponible para que los alumnos también puedan llevar los libros a casa, animándolos a envolver a la familia en sus lecturas. La propuesta se realiza en dos encuentros por semana. En las primeras acciones de la intervención pedagógica que está en marcha, la mayoría de los alumnos ya demuestra interés y participa activamente. Palabras clave: formación de lectores; el gusto por la lectura; reconstrucción del espacio del aula.

\begin{abstract}
:
The present study presents reports and reports and reflections concerning the actions of the intervention proposal, a requirement from the Professional Master's in Education, which is being carried out with the 4th grade class from the EMEF Padre Pagliani in the town of Jaguarão, RS. The proposal has the main purpose to promote actions that foster the students to like reading, based on the reconstruction of the classroom space, and it is justified by the difficulty of developing activities related to reading, as well as due to the lack of interest by the students. During the organization of the proposal, a collection of books was acquired for the class through donations from the students and the purchase of some books by the teacher, with books which were different from the ones found at the school library. The intervention had as its first action the organization of the reading corner, followed by storytelling. Reading circles, literary picnic and role-plays will be organized. The classroom library is made available for the students so that they can take the books home, motivating them to involve their families in their readings. The proposal takes place twice a week. In the first actions of the pedagogical intervention, which is in progress, most students already show interest and participate actively.
\end{abstract}

Keywords: training of readers; taste for reading; reconstruction of the classroom space.

\title{
1. Introdução
}

O presente estudo apresenta relatos e reflexões sobre as três primeiras ações da proposta de intervenção, requisito do Mestrado Profissional em Educação, desenvolvida com a turma do $4^{\circ}$ ano da E.M.E.F. Padre Pagliani, situada na área centraldo município de Jaguarão, RS. A turma, da qual sou professora titular, é composta por 23 alunos com idade média de 10 anos.

Este estudo é parte de uma pesquisaintervenção de abordagem qualitativa. A perspectiva qualitativa considera, segundo Bogdan e Biklen (1994), os dados obtidos diretamente pelo pesquisador, através do contato com a situação estudada e pela análise realizada das informações que obteve. No caso desta pesquisa, o fato de vivenciar direta e diariamente as dificuldades de leitura dos alunos, justifica esta abordagem.

Por pesquisa do tipo intervenção entendem-se aquelas que segundo Damiani (2013), são aplicadas com o fim de auxiliar na solução de problemas práticos. Neste tipo de pesquisa, o pesquisador elabora sua prática de intervenção, aplica e posteriormente analisa os resultados obtidos.

A proposta tem como objetivo geral promover ações que despertem nos alunos o gosto pela leitura, partindo da reconstrução do espaço da sala de aula e justifica-se pela dificuldade em desenvolver atividades relacionadas à leitura, bem como pelo desinteresse dos alunos em se envolverem e participarem destas. 
Em minha prática docente muitas vezes me deparo com as dificuldades que os alunos apresentam, principalmente, no que se refere à interpretação de textos. Muitos deles não conseguem compreender o significado de propostas de atividades, das mais simples às mais complexas, em qualquer disciplina. Alguns, quando copiam do quadro, copiam letra a letra e não a palavra como um todo, também sua leitura é fragmentada.

Os desafios enfrentados pelos professores na sala de aula são muitos. A educação toma novos rumos, ganha novas formas a cada dia. É preciso estar em constante busca e atualização para realizar um trabalho que chame a atenção dos alunos e que desperte o gosto pelo conhecimento.

No entanto, algumas vezes, uma pequena mudança na metodologia de trabalho do professor, ou na forma de desenvolver ações simples e cotidianas da sala de aula, traz um resultado positivo em maior proporção do que o esperado. Foi o caso das ações aqui relatadas e que fizeram parte da proposta de intervenção, que foram desenvolvidas de maneira simples, com poucos recursos, envolvendo os alunos em todos os momentos. Assim, pequenas mudanças em minha prática pedagógica, foram de essencial importância para que a proposta se efetivasse de maneira satisfatória.

Foram utilizados como instrumentos de coleta de dados a observação participante, o diário de campo, fotografias e filmagens. A observação participante implica a interação entre investigador e investigado e visa coletar dados diretamente do contexto em que a pesquisa está sendo desenvolvida, ou seja, o pesquisador entra diretamente em contato com o grupo pesquisado e participa das atividades desenvolvidas. (Marconi \& Lakatos,2010)

No que se refere ao diário de campo, este serve para que o pesquisador registre diariamente suas percepções. De acordo com Minayo (2007), no diário de campo podem ser registrados todos os acontecimentos no decorrer da pesquisa, ou seja, observações sobre conversas informais, sobre o tema da pesquisa. Assim, este instrumento possibilita ao pesquisador, registrar os acontecimentos em tempo real, do início ao fim da pesquisa, em forma de anotações que podem ser utilizadas, posteriormente, quando já não estiver em sala de aula, para proceder a uma escrita mais detalhada da dinâmica vivida, envolvendo todos os registros, inclusive de gestos, expressões, falas e silêncios dos alunos.

Em relação às fotografias e filmagens, levei em conta o que estas possibilitam, pois elas permitem que o pesquisador obtenha dados que muitas vezes não são possíveis apenas com as anotações do diário de campo ou pela observação. Um exemplo é a vantagem da filmagem/vídeo que permite a visualização de quantas vezes for necessário o material gravado 
possibilitando certa exatidão na coleta de informações.(DIAS, A.R.M.; CASTILHO, K.C.; SILVEIRA, V.S. 2018)

Para a análise das três ações dialoguei com Lena Lois (2010), Fanny Abramovich (1989) e Rildo Cosson (2014).Também busquei respaldo teórico nos escritos de Maria Tereza Esteban (2002) eJesualdo Sosa (1978). O artigo foi organizado em três partes: introdução, desenvolvimento e análise das ações e considerações finais. A seguir, apresentarei o desenvolvimento e análise das ações.

\section{Desenvolvimento e análise das ações}

Ao construir a proposta de intervenção, apliquei com as crianças um questionário com perguntas abertas com o objetivo de identificar as concepções de leitura, o hábito de ler, o tipo de livro que liam, dentre outros aspectos. Ficou evidente que a maioria das crianças que tinha o hábito de ler gostava de ler gibis. Então, para que as ações fossem desenvolvidas, foi adquirido um acervo para a sala de aula com vários gibis e livros diferentes dos que a biblioteca da escola possui e adequados para a sua faixa etária, através de doações que foram feitas por amigos e alunos da turma, como também por livros que comprei.

Para descrever estas três ações não utilizarei os nomes dos alunos, eles serão representados por letras maiúsculas que representam as iniciais de seus nomes. A seguir, apresentarei os relatos das três primeiras ações da intervenção, bem como sua análise.

\subsection{Primeira Ação - A organização do espaço}

Ao chegar a uma sala de aula, a criança observa tudo que está ao seu redor. A escola em que trabalho não possui muitos recursos físicos. Dessa forma, fica a critério de cada professor a organização de sua sala. Esta é uma iniciativa fundamental, uma vez que professores e alunos passam boa parte de seu dia neste espaço. É ali onde a intensidade de interações é maior, é o lugar no qual alunos e professores trocam, além de tudo, conhecimento, pois os alunos trazem suas experiências e suas leituras do mundo para aquele ambiente.

Nesse sentido, Esteban afirma que a sala de aula é um espaço plural que "deve criar condições para a interpretação das experiências múltiplas que os sujeitos trazem", assim, será favorecida "a apropriação das interpretações e conhecimentos que se mostrem necessários". (ESTEBAN, 2002, p. 133) 
A organização do espaço da sala de aula é um reflexo da ação do professor. Através desta organização o professor avalia a sua prática e escolhe a forma de trabalhar com seus alunos. Estas medidas também são necessárias no trabalho com a leitura.

Conforme Lois, "promover a ação da leitura é muito diferente de discursar sobre a leitura". Para esta autora "a sala de aula é repleta de pequenas e constantes surpresas" que desorganizam o planejamento do professor, mas que este precisa estar atento e aproveitar as oportunidades que surgem dessa desorganização. (LOIS, 2010, p.90)

Optei por organizar o cantinho da leitura na sala de aula, pois a biblioteca da escola funciona em uma sala muito pequena, não atrativa e com um acervo restrito, desatualizado e sem muitas opções de leitura. Desta forma, os alunos do $4^{\circ}$ ano teriam acesso a livros diferentes dos que a biblioteca possui em um ambiente construído com a participação deles, pois "consagrar a sala de aula como um espaço que promove alguns raros prazeres, como compartilhar uma boa leitura, é um bom começo para enredar o estudante numa rotina prazerosa e estreitar seus vínculos com a leitura" (LOIS, 2010, p. 84)

Assim, no primeiro dia da intervenção, os alunos organizaram o cantinho da leitura na sala de aula. Levei uma boneca em EVA que sugeri como mascote da turma para as atividades de leitura. Solicitei que os alunos escolhessem um nome para a boneca. Alguns nomes foram sugeridos pelos alunos: COLORIDINHA, LIVRINHA E LEITURINHA. Dentre as sugestões, escolheram "Leiturinha".

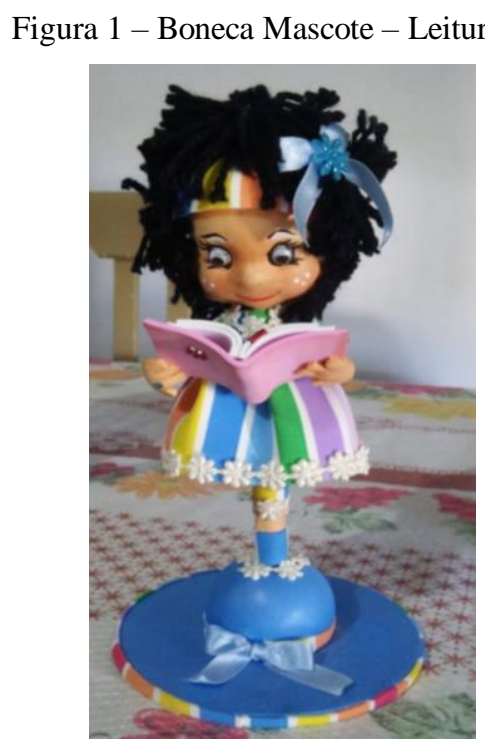

Fonte da autora.

Levei os livros em uma caixa que despertou a curiosidade das crianças. Em determinado momento pedi que eles retirassem o conteúdo da caixa. Quando abriram houve 
muitas exclamações e perguntas como: "Nossa! Que monte de livros!” - falou F - "Os que eu trouxe também estão aí?" - perguntou L - "Como tu conseguiu todos estes livros profe?" questionou I.

Então expliquei para eles que alguns livros haviam sido doados por colegas da sala de aula, outros por pessoas que eu conhecia e outros eu havia comprado. Eles ficaram maravilhados, pois os livros que tínhamos ali eram todos diferentes dos livros da biblioteca da escola.

Lois (2010) afirma que "para que as crianças respeitem um objeto e construam com ele uma relação de troca é necessário que elas convivam com esse objeto" (LOIS, 2010, p. 84). Nesse sentido, a organização do espaço também proporcionou o contato com os livros, uma vez que o cantinho da leitura foi organizado por eles. Os alunos manusearam, cheiraram, folhearam os livros. Então eu pedi que eles os organizassem.

O aluno JI tomou a frente e começou a organização, auxiliado pelas alunas B, I e AJ. Os primeiros a serem separados foram os gibis que eles classificaram em dois grupos: gibis da Turma da Mônica e diversos.

Figura 2 - alunos organizando os gibis.

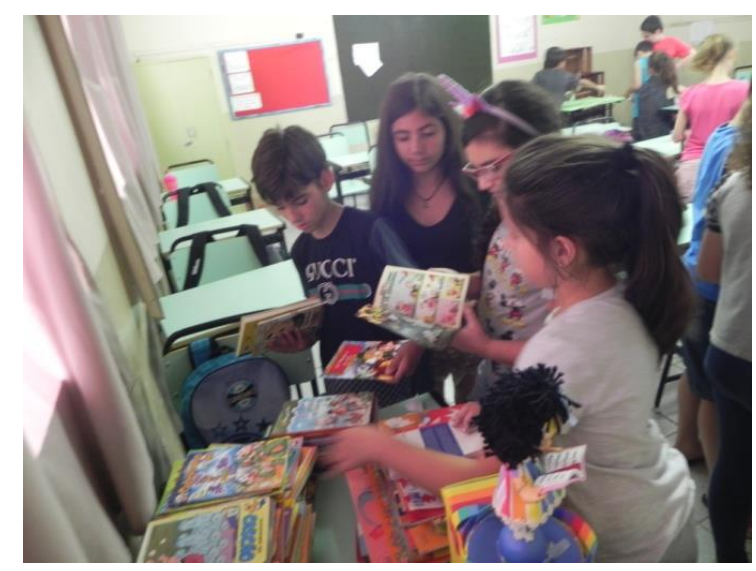

Fonte da autora.

Não estabeleci nenhum critério específico de classificação, pois os objetivos eram que os alunos se sentissem parte daquele processo e que eles manuseassem os livros. Dessa forma, começaria o envolvimento deles nas atividades, o que poderia ser um grande passo no desenvolvimento da ação.

Assim, outro grupo de alunos formado por K, C, G, AC, EM, começou a organizar os outros livros. Eles optaram por separá-los por tamanho ou por coleções. 


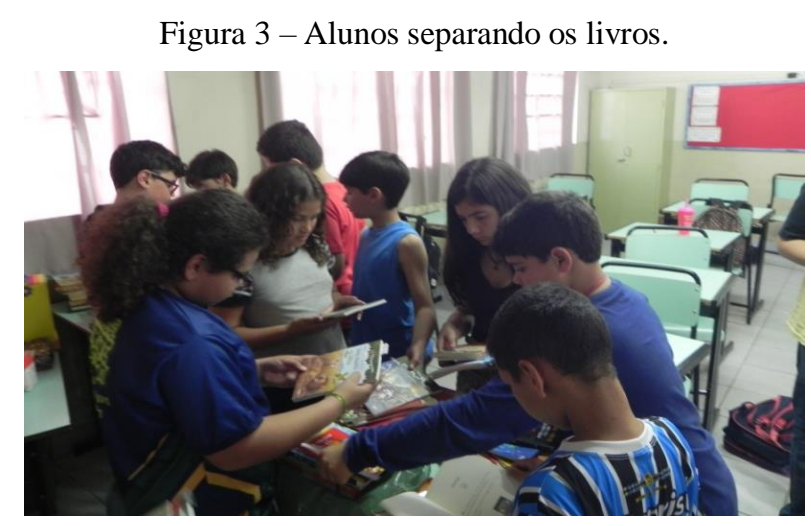

Fonte da autora.

Ao mesmo tempo, após o primeiro contato com os livros, os alunos M, RM, F e E, tomaram a iniciativa de anexar os cartazes confeccionados por mim para o cantinho da leitura que ficariam na parede acima da estante. Esta estante foi doada por amigos que tomaram conhecimento da necessidade de termos um lugar específico em aula para guardarmos os livros. Ela foi construída com caixas de frutas, dessas que encontramos em supermercados.

Figura 4 - Alunos colando os cartazes.

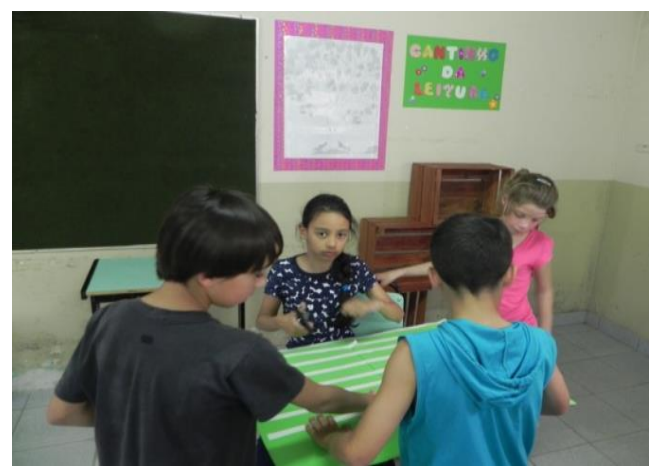

Fonte da autora.

Então, pedi que os alunos guardassem os livros na estante da forma como haviam organizado. Nosso cantinho da leitura ficou assim:

Figura 5 - Cantinho da Leitura.

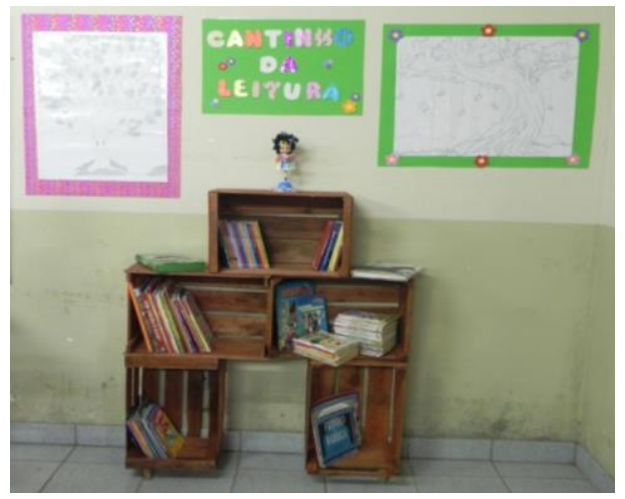

Fonte da autora.

Este foi o primeiro passo dado no caminho da formação de novos leitores em minha sala de aula, porque acredito que "um ambiente com livros, difere muito de um ambiente sem 
livros" (LOIS, 2010, p.54), pois o contato com eles proporciona um sentimento de boasvindas, ultrapassa barreiras do desconhecido e estimula o imaginário.

Para Lois "o livro possui multidões dentro de si e preenche grandes espaços, porque amplia os horizontes de quem se ocupa dele." A autora afirma que "há algo nos livros que atrai (...) os supostos não leitores", pois o livro "além de representar um objeto interessante, também possui a sedução das letras, que formam palavras, que formam parágrafos e que contam histórias mágicas.” (LOIS, 2010, p. 54)

A seguir, apresentarei o desenvolvimento e análise da segunda ação da intervenção.

\subsection{Segunda Ação - A primeira contação de história}

A arte de contar histórias é uma cultura milenar, que passa através dos tempos deixando marcas e perpetuando a narrativa humana. Segundo Abramovich (1989), através de uma história podemos descobrir outros lugares, outros tempos, outros jeitos de agir e de ser. É também momento de aprendizado conectado à diversão e prazer.

A história deste dia foi retirada do livro "Catando Piolhos Contando Histórias" de Daniel Munduruku Maté. A primeira lenda contada pelo autor nesta obra tem por título "Um lugar para todos". A escolha desta história se deu devido à importância, destacada ao longo do texto, à organização do trabalho em uma comunidade indígena, onde cada um desempenha seu papel, e principalmente pelas responsabilidades de cada um.

A dinâmica da contação de história foi organizada em dois momentos. O primeiro foi o da história recortada. Em uma caixa que utilizei como urna, coloquei a história recortada em tiras. Sentados em círculo os alunos, um a um, retiraram da urna uma tira do texto pela qual fica responsável de ler em voz alta para a turma. Conforme iam lendo, foi possível notar que estavam confusos, pois suas expressões evidenciavam isto.

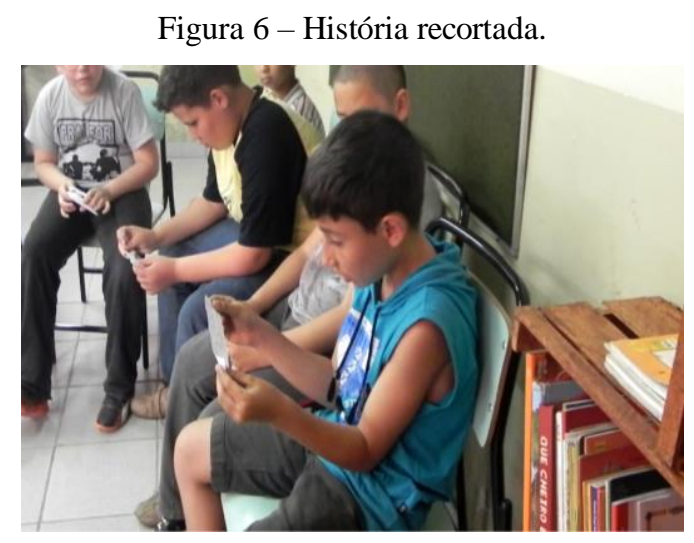

Fonte da autora. 
O objetivo desta atividade era o de auxiliar os alunos a perceberem que o texto tem uma organização. Assim, após a leitura, fiz alguns questionamentos sobre a história, pois precisava saber se eles tinham entendido o que acontecia. Com isto, ficou evidente que a maioria dos alunos não havia entendido a lenda, mas entenderam que ela estava "fora de ordem" como disse o aluno P.

O segundo momento consistia em organizar a história. Pedi ao aluno O que levantasse de seu lugar, pois ali sentaria quem estivesse com o primeiro parágrafo, e à medida que eu fosse lendo, eles pudessem sentar na ordem da leitura.

Assim, comecei a leitura e eles foram se organizando conforme os acontecimentos iam sendo narrados. Em alguns momentos, interrompi a leitura para auxiliá-los, pois alguns não conseguiam identificar sua parte do texto.

Ao término, os alunos aplaudiram entusiasmados. E começamos a conversa sobre a história. Perguntei o que eles tinham achado da atividade e, primeiramente o aluno L respondeu fatos relacionados à história como "morte, sacrifício, plantas". Então falei: "isso é relativo à história, me refiro à atividade, como a história estava antes?", ao que eles responderam vários ao mesmo tempo "a gente se juntou, a história tava separada, tava tudo desorganizado, tudo misturado". Como não havia entendido o que o aluno K falou, reforcei o que eles haviam dito e perguntei “o que mais K?" e ele respondeu: "a gente teve que ir juntando os pedaços" e falei ainda "a gente fez um trabalho em...", "GRUPO”, responderam os alunos em coro.

Segui questionando: "com o texto desorganizado como estava antes, a gente conseguiu entender a história?", "NÃO!" disseram todos, "Nada", disse O. Perguntei se depois que eu havia lido a história eles tinham entendido, eles responderam em uníssono novamente "SIM".

Foi uma contação dinâmica e participativa que tornou possível notar o interesse dos alunos durante o desenvolvimento da atividade. Dessa forma, vale ressaltar a importância de contar histórias para as crianças.

Ao contar histórias lidas, ouvidas, imaginadas, histórias de contos de fada, engraçadas, assustadoras ou de suspense, o professor promove a recuperação das narrativas populares e contribui na construção da memória coletiva. Vale salientar que "é importante para a formação de qualquer criança ouvir muitas histórias... Escutá-las é o início da aprendizagem para ser leitor, é ter um caminho absolutamente infinito de descobertas e de compreensão do mundo". (ABRAMOVICH, 1989, p. 16) 
Assim, partindo deste princípio, creio que o caminho estava sendo delineado para o desenvolvimento de mais atividades de contar histórias, pois ver o entusiasmo e a participação da turma foi o ponto culminante da tarde.

Encerrei a atividade, combinando com os alunos que no dia seguinte, eles poderiam levar os livros para casa para lerem. Houve palmas e vivas, muitas risadas, pois era o que eles mais vinham pedindo, desde o dia anterior.

Dessa forma, a seguir, relatarei como foi o primeiro empréstimo de livros.

\subsubsection{Primeiro empréstimo de livros}

Esta não era uma ação programada na construção da proposta de intervenção. Contudo, surgiu dos próprios alunos o interesse em levar os livros para casa. Assim, não a classifiquei como uma ação e sim como uma consequência positiva do que estava sendo desenvolvido, um resultado de um processo que estava apenas no início.

A ansiedade predominou neste dia, pois a todo o momento perguntavam quando poderiam escolher os livros. Alguns queriam reservar, visto que havia outros interessados no mesmo livro. Combinei então que eles poderiam escolher no último período da aula, pois assim eles teriam tempo para a escolha.

Chegado o momento, fui mandando dois alunos por vez na estante para escolherem o livro que queriam. Organizei um caderno para registrar o empréstimo com nome do aluno, título do livro, data do empréstimo e data de entrega, pois assim teria um controle e poderia perceber suas preferências.

Dos vinte e três alunos, quatorze levaram gibis para casa, seis levaram outros livros e apenas três não quiseram levar nenhum. Questionei o motivo e eles responderam que preferiam ler em aula. Não havia interesse em forçá-los, assim, não insisti, mas afirmei que quando mudassem de ideia poderiam escolher um livro.

A partir deste dia, as trocas foram acontecendo quase que diariamente, foi interessante ver que eles sugeriam os livros lidos para os colegas e, de forma gradativa, iam diversificando e lendo outros livros e não somente gibis, variando e despertando o gosto para outros estilos. E, o mais interessante, eles demonstraram um interesse cada vez maior pelos livros e também cuidaram e organizaram o cantinho da leitura sem que eu precisasse falar. Sem falar que em várias vezes os ouvia contando a algum dos colegas, a história que haviam lido.

Dessa forma, sem uma hierarquia rígida, sem imposições, o empréstimo de livros tornou possível resgatar a função primordial da leitura que busca "a recuperação do contato 
do aluno com a obra de ficção.” (ZILBERMAN, 1988, p.21) Assim criou-se um vínculo, democrático entre professor e aluno, com consequências relevantes, que tem o aluno como coparticipante, fortalecendo também o diálogo, aproximando-o de um conhecimento real que ao mesmo tempo, amplia suas possibilidades.

Para tanto, a reflexão do professor em sua prática diária deve estar sempre presente, pois um posicionamento crítico em seu fazer pedagógico faz com que esteja sempre em busca de novas práticas, novos objetivos e novos resultados.

Pensando assim, combinei com os alunos que a próxima ação seria na semana seguinte, mais precisamente no dia 31 de outubro. Neste momento o aluno P diz: "professora, dia 31 é dia das bruxas, vai ter que ser uma história de bruxa!". Novamente começa a agitação, pois queriam organizar uma festa de Halloween. Contudo, a história não poderia ser assustadora, teria que ser engraçada.

Já tinha em mente uma atividade diferente, mas visto que o objetivo da proposta é despertar o gosto pela leitura, achei pertinente o pedido e prometi que levaria uma história de bruxa que fosse engraçada. estudo.

A seguir, descreverei a terceira ação da intervenção, a última a ser analisada neste

\subsection{Terceira ação - Uma História de Bruxas}

Neste dia, conforme dito anteriormente a pedido dos alunos levei para contar a eles uma história de bruxas. Combinamos que após o recreio, faríamos a contação de história e em seguida, eles teriam sua festa.

Os alunos organizaram e decoraram a sala com o tema Halloween, levaram doces, caracterizaram-se de bruxos, bruxas, monstros ou vampiros e estavam ansiosos para a história.

Figura 7 e 8 - Espaço decorado para o Halloween.

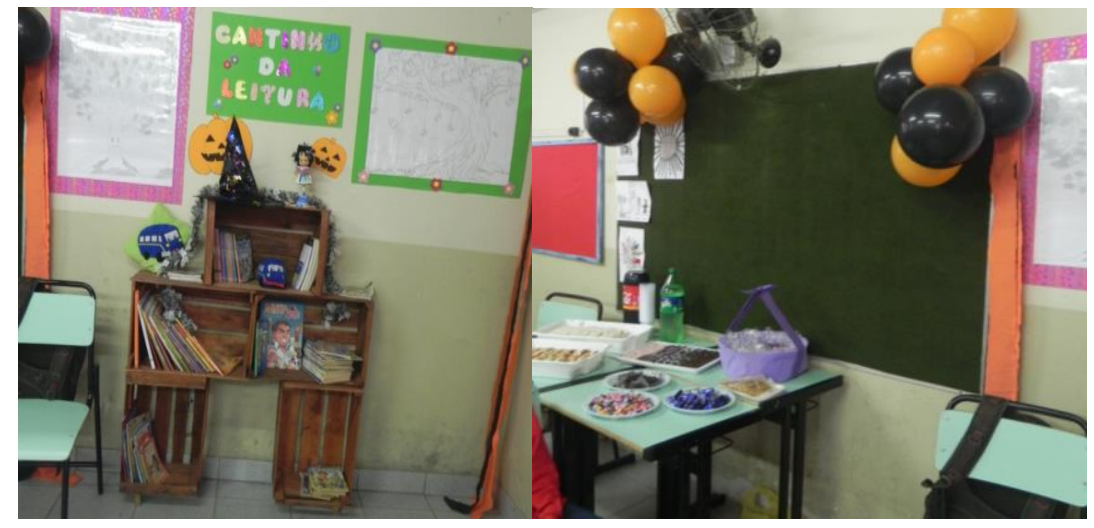

Fonte da autora. 
Para este dia, escolhi um texto com imagens e palavras. Nesta atividade precisaria da ajuda de alunos para filmar e para ler comigo a história. O texto era assim:

Figuras 9 e 10 - Recortes do texto sobre bruxas.
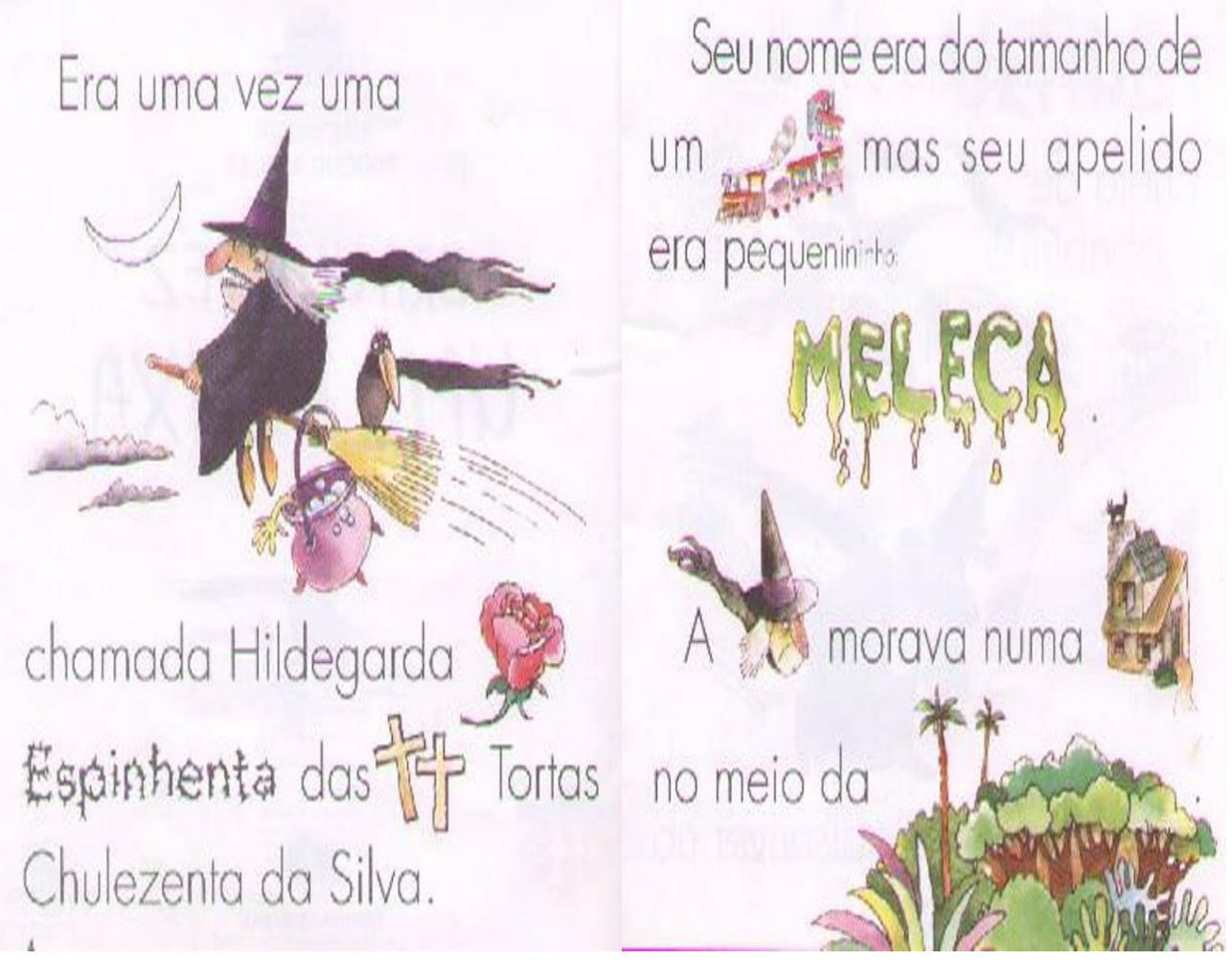

Fonte: http://www.minhaescolaweb.com.br/CONTOS/umabruxa.html

Inicialmente apenas eu lia, contudo, ao ir virando as páginas do livro, e por ser de um tamanho razoável que possibilitava aos alunos uma boa visualização, eles começaram a ler também. Às vezes eu lia as palavras e eles liam as imagens ou vice e versa.

O envolvimento da turma foi geral e todos queriam participar, pois um texto rico em imagens estimula o aluno a interpretar, ir além do que está escrito e construir sentidos ao texto.

Para Cosson "a narrativa tematiza o exercício da imaginação.” Para o autor o texto imagético "funciona como um contraponto ao que está escrito, mediando o mundo real e o mundo da fantasia" (COSSON, 2014, p.56)

Nesse mesmo sentido, vale ressaltar que

o livro interessante para criança deve recorrer ao caráter imaginoso: traduzidos em mitos, aparições da antiguidade, monstros ou realidades dos tempos modernos; exposto numa forma expressiva qualquer: lenda, conto, fábula, quadrinhos, etc.; descritos com beleza poética e ilustrações que mais sugerem do que dizem (SOSA, 1978, p. 37). 
Assim, trabalhar com texto imagético possibilitou às crianças diversas interpretações, pois cada uma delas atribuía um sentido ao texto, propiciando ao grupo várias leituras de uma mesma narrativa.

Dar um enfoque diferente às atividades de leitura com esta turma, trabalhando de forma que os momentos se transformassem em períodos agradáveis, nutridos de motivação e instigando a curiosidade das crianças foi imprescindível, pois desta forma, elas demonstraram interesse e sentiram-se parte do que estava acontecendo.

A seguir, apresento as considerações finais deste estudo.

\section{Considerações Finais}

Como professora dos anos iniciais busco tornar minhas aulas atrativas e envolventes. Priorizo a participação dos alunos em todas as atividades, pois acredito que dessa forma eles estarão de fato construindo seu conhecimento. Com a leitura não é diferente. Contudo, nestas atividades havia uma resistência por parte dos alunos.

Esta resistência aos poucos foi sendo substituída pela interação com o livro e com os colegas. No momento em que os alunos passaram a ter contato com os livros, eles passaram a interagir com seus colegas, muitas vezes contando o que haviam lido ou indicando algum livro.

Nesse sentido, Cosson afirma que "ao ler estou abrindo uma porta entre meu mundo e o mundo do outro", pois o ato de ler "implica troca de sentidos, não só entre o escritor e o leitor, mas também com a sociedade onde ambos estão localizados, pois os sentidos são resultados de compartilhamentos de visões do mundo entre os homens no tempo e no espaço." (COSSON, 2016, p. 27)

Vale ainda ressaltar que "ler é bem mais do que seguir uma linha de letras e palavras" (COSSON, 2016, p. 39), mas sim, atribuir sentidos ao texto, produzindo interpretações "por meio de um diálogo, uma conversa", pois "ler é um diálogo". (COSSON, 2014 p. 35)

Segundo Cosson (2014, p.168) o ato de ler é o encontro do leitor com a obra. No mesmo sentido Lois (2010, p.72) afirma que o texto não existe sem o leitor. Assim, na busca por caminhos para formar leitores, esta proposta de intervenção toma rumos positivos, despertando nos alunos o interesse e a participação, muitas vezes instantânea, nas atividades relacionadas à leitura. 


\section{Referências:}

ABRAMOVICH, Fanny. Literatura infantil: Gostosuras e bobices. São Paulo: Scipione, 1989.

BOGDAN, R.; BIKLEN, S. Investigação qualitativa em educação. Tradução de Antônio Branco Vasco. Porto: Porto Editora, 1994.

COSSON, Rildo. Círculos de Leitura e Letramento Literário. São Paulo: Contexto, 2014. Letramento Literário: teoria e prática. São Paulo: Contexto, 2016.

DAMIANI, Magda Floriana; ROCHEFORT, Renato Siqueira; CASTRO, Rafael Fonseca de; DARIZ, Marion Rodrigues; PINHEIRO, Silvia Siqueira. Discutindo pesquisas do tipo intervenção pedagógica. Cadernos de Educação FaE/PPGE/UFPel. Pelotas, n. 45, p. 57 - 67, jul. /ago. 2013.

DIAS, A.R.M.; CASTILHO, K.C.; SILVEIRA, V.S. Uso e Interpretação de Imagens e Filmagens em Pesquisa Qualitativa. Ensaios Pedagógicos (Sorocaba), vol.2, n.1, jan./abr. 2018, p.81-88 ISSN: 2527-158X

ESTEBAN, Maria Teresa. O que sabe quem erra? Reflexões sobre avaliação e fracasso escolar. 3. ed. Rio de Janeiro: DP\&A, 2002.

LOIS, Lena. Teoria e Prática da Formação do Leitor: leitura e literatura na sala de aula. Porto Alegre: Artmed, 2010.

MARCONI, M. \&LAKATOS, E. (2010). Metodologia científica. (5a ed.). São Paulo: Atlas.

SOSA, Jesualdo. A literatura infantil. Tradução de James Amado. São Paulo, Cultrix, Ed. da Universidade de São Paulo. 1978.

ZILBERMANN, Regina. A leitura na escola. In: ZILBERMANN, Regina. (Org.) Leitura em crise na escola: as alternativas do professor. 8.ed. Porto Alegre: Mercado Aberto, 1988. 